\title{
Pengaruh Stres Kerja dan Komunikasi Terhadap Kinerja Pegawai Dinas Perindustrian Dan Perdagangan Provinsi Jawa Tengah
}

\author{
Mar'atul Hidayah, Hasan dan Yulekhah Ariyanti* \\ Jurusan Manajemen, Fakultas Ekonomi, Universitas Wahid Hasyim \\ "Email: yulekhah@unwahas.ac.id
}

\begin{abstract}
This study aims to analyze the effect of knowledge, skills and abilities on the performance of the Eceng Gondok ISMB (Independent Micro Small Business) employees in Tuntang Regency. In this study the data used are primary data or questionnaires. The results showed that together there was a positive and significant influence of knowledge, skills and abilities on the performance of ISMB Eceng Gondok employees in Tuntang Regency.
\end{abstract}

Keywords: abilities, employee performance, knowledge, skills

\begin{abstract}
Abstrak
Penelitian ini bertujuan untuk menganalisis pengaruh stres kerja dan komunikasi terhadap kinerja pegawai Disperindag. Dalam penelitian ini data yang digunakan adalah data primer atau kuesioner. Hasil penelitian menunjukkan bahwa stres kerja berpengaruh tidak signifikan terhadap kinerja pegawai Disperindag, sedangkan komunikasi berpemgaruh terhadap kinerja pegawai Dinas Perindustrian dan Perdagangan Provinsi Jawa Tengah.
\end{abstract}

Kata kunci: Stres Kerja, Komunikas, Kinerja Pegawai

\section{PENDAHULUAN}

Pemerintah Indonesia terus berbenah dalam rangka meningkatkan citra, kerja dan kinerja instansi pemerintah menuju kearah profesionalisme, dan untuk menunjang terciptanya pemerintahan yang baik (good government), perlu adanya penyatuhan arah dan pandangan bagi segenap jajaran pemerintahan dan pandangan bagi segenap jajaran pegawai pemerintahan yang dapat dipergunakan sebagai pedoman atau acuan dalam melaksanakan tugas baik manajerial maupun oprasional diseluruh bidang tugas dan unit organisasi institusi pemerintah secara terpadu. Terkait dengan itu perlu dirumuskan visi, misi, strategi dan nilai acuan pemerintah yang menjadi pedoman mengenai arah yang dituju, beban tanggung jawab, strategi pencapaiannya serta nilainilai sikap dan prilaku aparat. Manajemen sumber daya manusia strategik mutlak diperlukan untuk mempersiapkan aparatur pemerintahan yang memahami visi dan misi organisasi. Perubahan yang sedang dan terus terjadi bukanlah sesuatu yang harus ditakuti, melainkan harus di hadapi dan diantisipasi.

Pengelolaan sumber daya manusia akan menjadi bagian penting dari tugas manajemen organisasi. Sebaliknya, jika sumber daya manusia tidak dikelola dengan baik maka efektivitas tidak akan tercapai. Sumber daya manusia bisa dijelaskan sebagai suatu pengelolaan dan pendayagunaan sumber daya pada tiap-tiap individu. Pengelolaan dan pendayagunaan tersebut dapat secara maksimal dikembangkan dalam dunia kerja untuk mencapai tujuan organisasi dan pengembangan individu (A.A. Anwar Prabu Mangkunegara 2013).

Kinerja pegawai merupakan suatu keseluruhan kemampuan seseorang untuk bekerja sedemikian rupa sehingga dapat mencapai tujuan kerja yang secara optimal serta dapat mencapai sasaran yang telah ditargetkan dan telah diukur secara rasio memiliki resiko yang kecil untuk mencapai sasaran (Siagian 2007 dalam Usailan Oemar 2017). Tingkat kinerja pegawai yang baik dan maksimal dapat dilihat dari bagaimana dalam suatu organisasi mengelola keadaan dalam lingkungan tersebut menjadi keadaan yang kondusif untuk dapat meningkatkan tingkat kinerja pegawai dengan baik. Salah satu upaya yang dapat dilakukan untuk perusahaan atau organisasi agr dapat mencapai tujuan yang elah dibuat sebelumnya yaitu dengan mengelola keadaan diri dalam seorang pegawai seperti penglolaan stres kerja dengan baik dan juga mengelola komunikasi dengan baik agar selama bekerja pegawai merasa nyaman dan dapat dengan segera menyelesaikan 
pekerjaan dengan baik dan sesuai dengan target atau tujuan organisasi atau perusahaan yang telah dibuat sebelumnya.

Stres adalah suatu kondisi dinamik yang didalamnya seorang individu dikonfrontasikan dengan suatu peluang, kendala (contraints), atau tuntutan (demands) yang dikaitkan dengan apa yang sangat diinginkannya dan yang hasilnya dipresepsikan sebagai tidak pasti dan penting (Schuller, 1980 dalam Edi Sasono 2004). Stres merupakan faktor fisik, kimiawi, dan emosional yang dapat menyebabkan tekanan pada tubuh atau mental dan dapat menjadi faktor bagi timbulnya penyakit. Stres juga merpakan interaksi individu dengan lingkungan, namun secara lebih terperinci stres merupakan suatu respon adaptif yang dihubungkan oleh perbedaan individu dan atau proses psikologi yang merupakan konsekuensi tindakan, situasi, atau kejadian eksternal (lingkungan) yang menempatkan tuntutan psikologi dan atau fisik secara berlebihan (Ivancevich dalam Luthans, 2006). Stres juga dideskripsikan sebagai tekanan pada tubuh atau mental yang melebihi batas kemampuan seseorang (Webster, dalam Price, 2003).

Selain pengelolaan stres kerja yang baik agar dapat meningkatkan kinerja pegawai yang baik pula, tiap-tiap organisasi juga harus memperhatikan kemampuan berkomunikasi dengan para anggota untuk tiap-tiap organisasi tersebut. Komunikasi adalah suatu proses pemindahan atau pertukaran informasi antara individu melalui sistem yang biasa atau lazim baik dengan simbulsimbul, sinyal-sinyal ataupun perilaku atau tindakan (Purwanto 2003). Komunikasi memilik peranan yang penting didalam suatu organisasi atau perusahaan. Dengan adanya komunikasi yang baik, suatu kegiatan perusahaan dapat berjalan dengan lancar dan begitu pula sebaliknya. Kurang atau tidak adanya komunikasi akan berakibat buruk bagi perusahaan (Dita Amanah 2012). Komunikasi merupakan suatu proses pemindahan pengertian dalam bentuk gagasan atau informasi dari satu orang ke orang lain. Perpindahan pengertian tersebut melibatkan lebih dari sekedar katakata yang dipergunakan dalam percakapan, ekspresi wajah, intonasi dan sebagainya. Wiryanto (2004).

Penelitian sebelumnya tentang stres kerja didefinisikan sebagai bentuk dari perasaan tertekan, ketidaknyamanan, ketidakmudahan, dan hambatan yang dirasakan secara emosional (Barone et. al, 1984 dalam Adityo Nugroho, 2008). Sebuah survey atas pekerja di Amerika Serikat menemukan bahwa 46 persen pekerja merasakan pekerjaan mereka penuh dengan stress dan 34 persen pekerja berpikir untuk keluar dari pekerjaan mereka 12 bulan sebelumnya karena stress di tempat kerja (Schellhardt, 1996 dalam Eko Sasono, 2004). Sedangkan penelitian yang telah dilakukann sebelumnya mengenai bagaimana pengaruh komunikasi terhadap kinerja yang dilakukan oleh Arie Puspita Wardhani, dkk (2016) dengan judul penelitian "Pengaruh Lingkungan Kerja, Komunikasi dan Kepemimpinan terhadap Kinerja Kaaryawan". Penelitian ini diolah dengan menggunakan SPSS dengan hasil bahwa variabel lingkungan kerja memberikan pengaruh positif, sehingga apabila lingkungan ditata dengan desain interior ruang yang memikat, serta sirkulasi udara yang bebas maka ruangan tersebut akan terasa nyaman untuk menyelesaikan pekerjaan. Begitu pula dengan variabel komunikasi dan kepemimpinana, apabila komunikasi terjalin dengan baik dan efektif antar sesama karyawan atau atasan, maaka hal tersebut dapat memberikan efek yang baik untuk kinerja yang akan dihasilkan nanti, begitu pula dengan kepemimpinan yang diberikan oleh atasa, jika atasan dapat memberikan kepemimpinan yang baik maka para karyawan akan merasa nyaman ketika bekerja. Berdasarkan uraian diatas maka tujuan dalam penelitian ini adalah untuk membuktikan dan menganalisis pengaruh stres kerja dan komunikasi terhadap kinerja pegawai Dinas Perindustrian dan Perdagangan Provinsi Jawa Tengah

\section{METODE PENELITIAN}

Penelitian ini penulis menggunakan metode kuantitatif yakni metode yang menggunakan pendekatan pengukuran atau numerik terhadap masalah yang hendak diteliti dan juga pada pengumpulan data dan analisis data. Metode yang digunakan umumnya metode survey yang mendalam dan dapat mengkaji isu-isu yang luas. AdapunVariabel-variabel yang digunakan dalam penelitian ini antara lain, variabel bebas (independent variable) terdiri dari stres kerja (X1) dan komunikasi (X2). Sedangkan variabel terikat (dependent variable) adalah kinerja pegawai (Y). Populasi dalam penelitian ini adalah seluruh pegawai Dinas Perindustrian dan Perdagangan Provinsi Jawa Tengah. Sedangkan sampel dalam penelitian ini berjumlah 62 responden yang diambil dengan menggunakan rumus dari Slovin. 


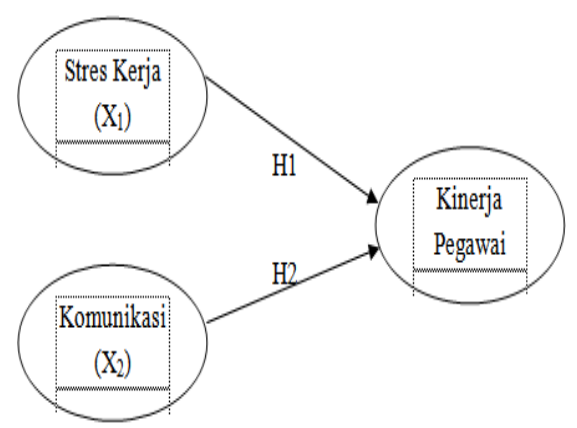

Gambar 1. Kerangka Berpikir

Sumber : Analisa Penulis dari Berbagai Jurnal

Penelitian ini menggunakan jenis data kuantitatif yaitu data yang diperoleh dalam bentuk angka yang dapat dihitung. Data yang digunakan penulis adalah data primer atau kuisioner. Perolehan data serta keterangan yang diperlukan dalam penelitian ini, penulis menggunakan teknik pengumpulan data melalui kuesioner, yaitu teknik pengumpulan data dengan jalan mengumpulkan data dari para responden dan studi kepustakaan, yaitu penelitian yang dilakukan dengan cara mengumpulkan data melalui beberapa literatur, artikel, karya ilmiah dan bahan analisis yang berkaitan dengan penelitian ini. Metode analisis data yang digunakan adalah uji validitas, uji reliabilitas, uji asumsi klasik (uji normalitas, uji multikolinearitas dan uji heterokedastisitas), analisis regresi linear.

\section{HASIL DAN PEMBAHASAN}

Responden dalam penelitian ini adalan pegawai Dinas Perindustrian dan Perdagangan Provinsi Jawa Tengah yang berjumlah 62 orang. Kuesioner yang berjumlah 62 kuesioner telah diberikan kepada pegawai yang menjadi sampel dalam penelitian ini. Keseluruhan kuesioner dianggap layak untuk diuji karena diisi dengan lengkap dan benar. Gambaran umum responden dalam penelitiana ini meliputi tingkat stres kerja dan komunikasi. Profil responden dalam penelitian ini terdapat lebih banyak atau didominasi oleh laki-laki dan responden pegawai yang paling dominann lama bekerja dalam penelitian ini yaitu lebih dari 15 tahun.

Tabel 1. Karakteristik Responden Berdasarkan Jenis Kelamin

\begin{tabular}{|l|c|c|c|}
\hline No. & Jenis Kelamin & Frekuensi & Persentase (\%) \\
\hline 1. & Laki-laki & 34 & $55 \%$ \\
\hline 2. & Perempuan & 28 & $45 \%$ \\
\hline \multicolumn{2}{|c|}{ Jumlah } & 62 & $100 \%$ \\
\hline
\end{tabular}

Sumber: Data Primer, 2019

Tabel 2. Karakteristik Responden Berdasarkan Lama Bekerja

\begin{tabular}{|c|c|c|c|}
\hline No. & Lama Bekerja & Jumlah & Persentase (\%) \\
\hline 1. & $2-5$ Tahun & 7 & $11 \%$ \\
\hline 2. & $6-10$ Tahun & 12 & $19 \%$ \\
\hline 3. & $10-15$ Tahun & 11 & $18 \%$ \\
\hline 4. & Lebih dari 15 Tahun & 32 & $52 \%$ \\
\hline & Jumlah & 62 & $100 \%$ \\
\hline
\end{tabular}

Sumber: Data Primer, 2019 
Variabel stres kerja diukur melalui 6 indikator. Hasil tanggapan terhadap stres kerja dijelaskan dalam tabel 3 berikut ini:

Tabel 3. Tanggapan Responden Mengenai Stres Kerja

\begin{tabular}{|c|c|c|c|c|c|c|c|c|}
\hline \multirow{2}{*}{ No } & \multirow{2}{*}{ Indikator } & \multirow{2}{*}{ Pertanyaan } & \multicolumn{5}{|c|}{ Skor } & \multirow{2}{*}{ Jumlah } \\
\hline & & & SS & $\mathbf{S}$ & KS & TS & STS & \\
\hline \multirow{4}{*}{1} & \multirow{4}{*}{$\begin{array}{l}\text { Ketegangan } \\
\text { dalam bekerja }\end{array}$} & $\mathrm{X} 1.1$ & 19 & 39 & 3 & 1 & & 62 \\
\hline & & & $31 \%$ & $63 \%$ & $5 \%$ & $1 \%$ & & $100 \%$ \\
\hline & & $\mathrm{X} 1.2$ & 10 & 45 & 5 & 2 & & 62 \\
\hline & & & $16 \%$ & $73 \%$ & $8 \%$ & $3 \%$ & & $100 \%$ \\
\hline \multirow{4}{*}{2} & \multirow{4}{*}{$\begin{array}{l}\text { Keluhan } \\
\text { penyakit }\end{array}$} & $\mathrm{X} 1.3$ & 12 & 43 & 6 & 1 & & 62 \\
\hline & & & $19 \%$ & $70 \%$ & $10 \%$ & $1 \%$ & & $100 \%$ \\
\hline & & $\mathrm{X} 1.4$ & 13 & 41 & 7 & 1 & & 62 \\
\hline & & & $21 \%$ & $67 \%$ & $7 \%$ & $1 \%$ & & $100 \%$ \\
\hline \multirow{4}{*}{3} & \multirow{4}{*}{$\begin{array}{l}\text { Emosi tidak } \\
\text { stabil }\end{array}$} & $\mathrm{X} 1.5$ & 7 & 21 & 17 & 16 & 1 & 62 \\
\hline & & & $11 \%$ & $34 \%$ & $28 \%$ & $26 \%$ & $1 \%$ & $100 \%$ \\
\hline & & $\mathrm{X} 1.6$ & 7 & 37 & 16 & 2 & & 62 \\
\hline & & & $11 \%$ & $60 \%$ & $28 \%$ & $3 \%$ & & $100 \%$ \\
\hline \multirow{4}{*}{4} & \multirow{4}{*}{$\begin{array}{l}\text { Ketidakpuasan } \\
\text { dalam bekerja }\end{array}$} & $\mathrm{X} 1.7$ & 3 & 31 & 25 & 3 & & 62 \\
\hline & & & $5 \%$ & $50 \%$ & $40 \%$ & $5 \%$ & & $100 \%$ \\
\hline & & $\mathrm{X} 1.8$ & 1 & 28 & 32 & 1 & & 62 \\
\hline & & & $1 \%$ & $46 \%$ & $52 \%$ & $1 \%$ & & $100 \%$ \\
\hline \multirow{4}{*}{5} & \multirow{4}{*}{$\begin{array}{c}\text { Perubahan } \\
\text { perilaku }\end{array}$} & X1.9 & 6 & 43 & 11 & 2 & & 62 \\
\hline & & & $10 \%$ & $69 \%$ & $18 \%$ & $3 \%$ & & $100 \%$ \\
\hline & & $\mathrm{X} 1.10$ & 6 & 31 & 18 & 7 & & 62 \\
\hline & & & $10 \%$ & $50 \%$ & $29 \%$ & $11 \%$ & & $100 \%$ \\
\hline \multirow{4}{*}{6} & \multirow{4}{*}{$\begin{array}{l}\text { Penurunan } \\
\text { kinerja }\end{array}$} & $\mathrm{X} 1.11$ & 3 & 23 & 12 & 24 & & 62 \\
\hline & & & $5 \%$ & $37 \%$ & $19 \%$ & $39 \%$ & & $100 \%$ \\
\hline & & $\mathrm{X} 1.12$ & 3 & 31 & 25 & 3 & & 62 \\
\hline & & & $5 \%$ & $50 \%$ & $40 \%$ & $5 \%$ & & $100 \%$ \\
\hline
\end{tabular}

Sumber: Data Primer, 2019

Berdasarkan tabel 4.5 diatas menyatakan bahwa pegawai yang paling dominan memilih terdapat pada indikator yang pertama tentang ketegangan dalam bekerja, sedangkan yang paling rendah yaitu pada indikator emosi tidak stabil. Sedangkan, variabel komunikasi diukur dengan menggunakan 5 indikator. Hasil tanggapan terhadap komunikasi dapat dijelaskan pada tabel 4 berikut: 
Tabel 4. Tanggapan Responden Mengenai Komunikasi

\begin{tabular}{|c|c|c|c|c|c|c|c|c|}
\hline \multirow{2}{*}{ No } & \multirow{2}{*}{ Indikator } & \multirow{2}{*}{ Pertanyaan } & \multicolumn{5}{|c|}{ Skor } & \multirow{2}{*}{ Jumlah } \\
\hline & & & SS & $\mathbf{S}$ & KS & TS & STS & \\
\hline \multirow{4}{*}{1} & \multirow{4}{*}{ Pemahaman } & $\mathrm{X} 2.1$ & 11 & 47 & 4 & & & 62 \\
\hline & & & $18 \%$ & $76 \%$ & $6 \%$ & & & $100 \%$ \\
\hline & & $\mathrm{X} 2.2$ & 17 & 45 & & & & 62 \\
\hline & & & $27 \%$ & $73 \%$ & & & & $100 \%$ \\
\hline \multirow{4}{*}{2} & \multirow{4}{*}{ Kesenangan } & $\mathrm{X} 2.3$ & 12 & 47 & 3 & & & 62 \\
\hline & & & $19 \%$ & $76 \%$ & $5 \%$ & & & $100 \%$ \\
\hline & & $\mathrm{X} 2.4$ & 11 & 47 & 4 & & & 62 \\
\hline & & & $18 \%$ & $76 \%$ & $6 \%$ & & & $100 \%$ \\
\hline \multirow{4}{*}{3} & \multirow{4}{*}{$\begin{array}{l}\text { Pengaruh } \\
\text { pada sikap }\end{array}$} & $\mathrm{X} 2.5$ & 7 & 23 & 32 & & & 62 \\
\hline & & & $11 \%$ & $37 \%$ & $52 \%$ & & & $100 \%$ \\
\hline & & $\mathrm{X} 2.6$ & 17 & 45 & & & & 62 \\
\hline & & & $27 \%$ & $73 \%$ & & & & $100 \%$ \\
\hline \multirow{4}{*}{4} & \multirow{4}{*}{$\begin{array}{l}\text { hubungan } \\
\text { yang makin } \\
\text { baik }\end{array}$} & $\mathrm{X} 2.7$ & 15 & 38 & 9 & & & 62 \\
\hline & & & $24 \%$ & $61 \%$ & $15 \%$ & & & $100 \%$ \\
\hline & & $\mathrm{X} 2.8$ & 14 & 45 & 3 & & & 62 \\
\hline & & & $23 \%$ & $72 \%$ & $5 \%$ & & & $100 \%$ \\
\hline \multirow{4}{*}{5} & \multirow{4}{*}{ Tindakan } & $\mathrm{X} 2.9$ & 12 & 40 & 8 & 2 & & 62 \\
\hline & & & $19 \%$ & $65 \%$ & $13 \%$ & $3 \%$ & & $100 \%$ \\
\hline & & $\mathrm{X} 2.10$ & 12 & 45 & 5 & & & 62 \\
\hline & & & $19 \%$ & $73 \%$ & $8 \%$ & & & $100 \%$ \\
\hline
\end{tabular}

Sumber: Data Primer, 2019

Berdasarkan tabel diatas, dapat diambil suatu kesimpulan bahwa responden yang paling dominan memilih yaitu pada indikator tentang pemahaman, sedangkan yang paling rendah memilih yaitu pada indikator tindakan.Adapun variabel kinerja pegawai dapat diukur menggunakan 6 indikator. Hasil tanggapan terhadap kinerja pegawai dapat dijelaskan pada tabel berikut ini:

Tabel 5. Tanggapan Responden Mengenai Kinerja Pegawai

\begin{tabular}{|c|c|c|c|c|c|c|c|c|}
\hline \multirow{2}{*}{ No } & \multirow{2}{*}{ Indikator } & \multirow{2}{*}{ Pertanyaan } & \multicolumn{5}{|c|}{ Skor } & \multirow{2}{*}{ Jumlah } \\
\hline & & & SS & $\mathbf{S}$ & KS & TS & STS & \\
\hline \multirow{4}{*}{1} & \multirow{4}{*}{$\begin{array}{c}\text { Sasaran kerja } \\
\text { pegawai }\end{array}$} & $\mathrm{Y} 1.1$ & 19 & 43 & & & & 62 \\
\hline & & & $31 \%$ & $69 \%$ & & & & $100 \%$ \\
\hline & & $\mathrm{Y} 1.2$ & 12 & 45 & 5 & & & 62 \\
\hline & & & $19 \%$ & $73 \%$ & $8 \%$ & & & $100 \%$ \\
\hline \multirow{4}{*}{2} & \multirow{4}{*}{$\begin{array}{l}\text { Orientasi } \\
\text { Pelayanan }\end{array}$} & $\mathrm{Y} 1.3$ & 9 & 48 & 5 & & & 62 \\
\hline & & & $15 \%$ & $77 \%$ & $8 \%$ & & & $100 \%$ \\
\hline & & Y1.4 & 12 & 43 & 7 & & & 62 \\
\hline & & & $19 \%$ & $69 \%$ & $12 \%$ & & & $100 \%$ \\
\hline \multirow{4}{*}{3} & \multirow{4}{*}{ Integritas } & $\mathrm{Y} 1.5$ & 15 & 32 & 12 & 3 & & 62 \\
\hline & & & $24 \%$ & $52 \%$ & $19 \%$ & $5 \%$ & & $100 \%$ \\
\hline & & Y1.6 & 20 & 39 & 3 & & & 62 \\
\hline & & & $32 \%$ & $63 \%$ & $5 \%$ & & & $100 \%$ \\
\hline
\end{tabular}




\begin{tabular}{|c|c|c|c|c|c|c|c|c|}
\hline \multirow{2}{*}{ No } & \multirow{2}{*}{ Indikator } & \multirow{2}{*}{ Pertanyaan } & \multicolumn{5}{|c|}{ Skor } & \multirow{2}{*}{ Jumlah } \\
\hline & & & SS & $\mathbf{S}$ & KS & TS & STS & \\
\hline \multirow{4}{*}{4} & \multirow{4}{*}{ Komitmen } & Y1.7 & 11 & 22 & 27 & 2 & & 62 \\
\hline & & & $18 \%$ & $35 \%$ & $44 \%$ & $3 \%$ & & $100 \%$ \\
\hline & & Y1.8 & 11 & 33 & 18 & & & 62 \\
\hline & & & $18 \%$ & $53 \%$ & $29 \%$ & & & $100 \%$ \\
\hline \multirow{4}{*}{5} & \multirow{4}{*}{ Disiplin } & Y1.9 & 3 & 20 & 24 & 15 & & 62 \\
\hline & & & $5 \%$ & $32 \%$ & $39 \%$ & $24 \%$ & & $100 \%$ \\
\hline & & $\mathrm{Y} 1.10$ & 5 & 29 & 18 & 10 & & 62 \\
\hline & & & $8 \%$ & $47 \%$ & $29 \%$ & $16 \%$ & & $100 \%$ \\
\hline \multirow{4}{*}{6} & \multirow{4}{*}{ Kerja Sama } & Y1.11 & 6 & 44 & 12 & & & 62 \\
\hline & & & $10 \%$ & $71 \%$ & $19 \%$ & & & $100 \%$ \\
\hline & & $\mathrm{Y} 1.12$ & 13 & 31 & 18 & & & 62 \\
\hline & & & $21 \%$ & $50 \%$ & $29 \%$ & & & $100 \%$ \\
\hline
\end{tabular}

sumber: Data Primer, 2019

Berdasarkan tabel diatas menujukkan bahwa responden yang paling banyak memilih yaitu paada indikator sasaran kerja pegawai pada tahun 2018, sedangkan yang paling rendah yaitu pada indikator komitmen pada tahun 2018. Dalam menguji hipotesis terlebih dahulu diperlukan analisis regresi linier. Berikut tabel yang menunjukkan hasil analisis regresi linier:

Tabel 6. Hasil Estimasi Regresi Coefficients $^{\mathrm{a}}$

\begin{tabular}{|c|c|c|c|c|c|c|}
\hline & \multirow{2}{*}{ Model } & \multicolumn{2}{|c|}{ Unstandardized Coefficients } & $\begin{array}{l}\text { Standardized } \\
\text { Coefficients }\end{array}$ & \multirow{2}{*}{$\mathrm{T}$} & \multirow{2}{*}{ Sig. } \\
\hline & & B & Std. Error & Beta & & \\
\hline \multirow[t]{3}{*}{1} & (Constant) & 2,203 & 6,312 & & ,349 &, 728 \\
\hline & Stres Kerja &, 051 & 096 & ,049 &, 533 &, 596 \\
\hline & Komunikasi & 1,057 & ,136 & ,712 & 7,760 &, 000 \\
\hline
\end{tabular}

a. Dependent Variable: Kinerja Pegawai

Sumber: Lampiran Output SPSS

Berdasarkan tabel 4.11 diatas, maka didapatkan suatu persamaan regresi sebagai berikut:

$$
\begin{aligned}
& Y=a+b 1 X_{1}+b 2 X_{2} \\
& Y=2,203+0,049 X_{1}+0,712 X_{2}
\end{aligned}
$$

Berdasarkan persamaan regresi, maka diketahui bahwa nilai konstantanya adalah 2,203. Besarnya pengaruh yang diberikan variabel stres kerja (X1) sebesar 0,049 dan besarnya pengaruh yang diberikan variabel komunikasi sebesar 0,712 .

Tabel 7. Hasil Uji T

\begin{tabular}{|c|c|c|}
\hline Variabel Bebas & T hitung & Sig. \\
\hline Stres kerja (X1) & 0,533 & 0,596 \\
\hline Komunikasi (X2) & 7,760 & 0,000 \\
\hline
\end{tabular}

Sumber: Output SPSS

Hasil dari pengujian menggunakan SPSS versi 22 menunjukkan t-hitung sebesar 0,533 < ttabel sebesar 1,67065 dengan taraf signifikansi sebesar 0,596 >0,05 yang berarti variabel stres kerja dalam penelitian ini tidak berpengaruh signifikan terhadap variabel kinerja pegawai pada Dinas Perindustrian dan Perdagangan Provinsi Jawa Tengah. Sedangkan untuk pengujian 
komunikasi menunjukkan bahwa hasil t-hitung sebesar 7,760 > t-tabel 1,67065 dengan taraf signifikansi $0,00<0,05$ yang berarti variabel komunikasi dalam penelitian ini berpengaruh terhadap kinerja pegawai Dinas Perindustrian dan Perdagangan Provinsi Jawa Tengah.

Uji F (Model) digunakan dengan tujuan untuk mengetahui apakah model yang dipakai cocok atau tidak dalam penelitian ini. Uji ini dapat diterima atau cocok untuk digunakan jika hasil dari fhitung lebih besar dari f-tabel sebesar 3,18 dengan taraf signifikansi lebih kecil dari 0,05. Hasil perhitungan statistik menunjukkan nilai f-hitung sebesar 30,112 dimana nilai tersebut lebih besar dari f-tabel sebesar 3,18 dan dengan nilai signifikansi sebesar 0,000 dimana nilai tersebut lebih kecil dari 0,05. Sehingga dapat disimpulkan bahwa model dalam penelitian ini cocok digunakan untuk penelitian.

\section{Tabel 8. Uji F}

ANOVA $^{\mathrm{a}}$

\begin{tabular}{|c|c|c|c|c|c|}
\hline Model & Sum of Squares & $\overline{\mathrm{Df}}$ & Mean Square & $\bar{F}$ & Sig. \\
\hline Regression & 985,538 & 2 & 492,769 & 30,112 &, $000^{\mathrm{b}}$ \\
\hline Residual & 965,510 & 59 & 16,365 & & \\
\hline Total & 1951,048 & 61 & & & \\
\hline
\end{tabular}

a. Dependent Variable: Kinerja Pegawai

b. Predictors: (Constant), Komunikasi, Stres Kerja

Sumber: Lampiran Hasil Output SPSS

Pada uji koefisien Determinasi ini dapat dilihat seberapa besar banyaknya pengaruh stres kerja dan komunikasi terhadap kinerja pegawai Dinas Perindustrian dan Perdagangan Provinsi Jawa Tengah. Hasil perhitungan regresi dapat diketahui bahwa koefisien determinasi (adjusted $R^{2}$ ) yang diperoleh sebesar 0,488 . Hal ini berarti sebesar $48,8 \%$ variasi kinerja pegawai dapat dijelaskan oleh variabel stres kerja dan komunikasi. Sedangkan 51,2\% (100\% - 48,8\%) diterangkan oleh variabel lai yang tidak diajukan dalam penelitian ini.

Tabel 9. Koefisien Determinasi Model Summary

\begin{tabular}{|c|r|r|r|r|}
\hline Model & $\mathrm{R}$ & \multicolumn{1}{|c|}{ R Square } & Adjusted R Square & $\begin{array}{c}\text { Std. Error of the } \\
\text { Estimate }\end{array}$ \\
\hline 1 &, $711^{\mathrm{a}}$ &, 505 &, 488 & 4,04532 \\
\hline
\end{tabular}

a. Predictors: (Constant), Komunikasi, Stres Kerja

Sumber: Lampiran Output SPSS

Dari hasil analisa diatas maka hipotesis dalam penelitian ini dapat diketahui sebagai berikut:

1. Hipotesis pertama menyatakan bahwa ada pengaruh tidak signifikan stres kerja terhadap kinerja pegawai Dinas Perindustrian dan Perdagangan Provinsi Jawa Tengah.

2. Hipotesis yang kedua menyatakan bahwa ada pengaruh signifikan komunikasi terhadap kinerja pegawai Dinas Perindustrian dan Perdagangan Provinsi Jawa Tengah.

\section{KESIMPULAN}

Dari data primer yang diperoleh dari penyebaran kesioner, maka dilakukan pengujian validitas untuk mengukur valid tidaknya suatu kuesioner. Kemudian dilakukan pengujian reliabilitas untuk mengetahui bahwa jawaban responden terhadap pernyataan konsisten dari waktu kewaktu. Dalam uji asumsi klasik yang meliputi uji normalitas, uji multikolinearitas dan uji heterokedastisitas menunjukkan bahwa kuesioner berdistribusi secara normal, tidak terjadi korelasi antar variabel bebas dan tidak terjadi heterokedastisitas. Dari pemabahasan yang telah diuraikan, maka dapat ditarik kesimpulan sebagai berikut:

Hasil pengujian hipotesis $\mathrm{H} 1$ yang dilakukan membuktikan bahwa tidak adanya pengaruh yang tidak signifikan antara variabel stres kerja terhadap kinerja pegawai. Dilihat dari hasi perhitungan yang diperoleh t-hitung sebesar $0,533<\mathrm{t}$-tabel 1,67065 dengan taraf signifikansi sebesar 0,596 > 0,05. Berdasarkan hal tersebut maka Ha ditolak dan H0 diterima, dapat 
disimpulkan bahwa stres kerja tidak berpengaruh signifikan terhadap kinerja pegawai Dinas Perindustrian dan Perdagangan Provinsi Jawa Tengah.

Hasil pengujian hipotesi $\mathrm{H} 2$ yang dilakukan membuktikan bahwa ada pengaruh yang signifikan antara variabel komunikasi terhadap kinerja pegawai. Dilihat dari hasil perhitungan yang diperoleh yaitu t-hitung sebesar 7,760 > t-tabel 1,67065 dengan taraf signifkansi sebesar 0,000 < 0,05. Berdasarkan hal tersebut maka Ha diterima dan HO ditolak, sehingga dapat disimpulkan bahwa komunikasi berpengaruh signifikan terhadap kinerja pegawai Dinas Perindustrian dan Perdagangan Provinsi Jawa Tengah.

Berdasarkan hasil penelitian, pembahasan dan kesimpulan yang menujukkan bahwa variabel stres kerja tidak berpengaruh terhadap kinerja pegawai pada Dinas Perindustrian dan Perdagangan Provinsi Jawa Tengah, maka disarankan pihak instansi lebih memperhatikan apa yang menjadi kebutuhan dan keinginan pegawai terutama dalam hal atau kondisi diri pegawai masing-masing agar dapat menikatkan kinerjanya semaksimal mungkin. Selain itu Dinas Perindustrian dan Perdagangan Provinsi Jawa Tengah juga harus memperhatikan komunikasi yang ada karena variabel tersebut berpengaruh terhadap kinerja pegawai. Tentunya kinerja pegawai akan lebih baik apabila dapat lebih meningkatkan pemahaman dalam bekerja melalui komunikasi yang terjalin dengan baik sehingga tidak terjadi kesalah pahaman dalam menerima berita informasi melalui komunikasi yang terjalin.

Penelitian ini dapat dilakukan kembali dengan objek penelitian yang berbeda dengan item pertanyaan pada kuesioner yang berbeda pula. Bagi peneliti selanjutnya dapat dimanfaatkan sebagai bahan rujukan dalam melakukan penelitian yang berkaitan dengan stres kerja dan komunikasi. Variabel dalam penelitian ini hanya menggunakan variabel stres kerja dan komunikasi. Sehingga disarankan untuk peneliti selanjutnya dapat meneliti dengan menggunakan variabel-variabel lain diluar variabel yang telah diteliti, agar memperoleh hasil yang variatif dan memperkaya teori yang ada.

\section{DAFTAR PUSTAKA}

Amanah, Dita. 2012. Pengaruh Lingkungan Kerja dan Komunikasi terhadap Kinerja Karyawan pada PT. United Tractors, Tbk Cabang Medan. UNIMED. Vol. 1. Ed. 2 Desember 2012.

Anoraga, Panji, 2001. Psikologi Kerja, Rineka Cipta, Jakarta.

Anwar Prabu Mangkunegara, 2013, Manajemen Sumber Daya Manusia Perusahaan, Remaja Rosdakarya, Bandung. Allen, 2014, Commitment in The Workplace Theory.

Purwanto, Ngalim, Psikologi Pendidikan, Bandung:PT Rosda Karya, 2003.

Puspita, Arie. 2016. Pengaruh Lingkungan Kerja, Komunikasi dan Kepemimpinan Terhadap Kinerja Pegawai Dinas Kebudayaan dan Pariwisata Kota Semarang. universitas Pandanaran, Semarang. Vol. 2. No. 2. Maret 2016.

Wiryanto. 2004. Pengantar Ilmu Komunikasi. Jakarta: PT. Gramedia Widasarana Indonesia 